\title{
Optimal Designing of Heavy Duty Vehicle Preheater System
}

\author{
Y.Z. Shao, Y. L, M. Li, H.L. Shi \\ State Key Laboratory of Automotive Simulation and Control \\ Jilin University \\ Changchun, China \\ College of Automotive Engineering \\ Jilin University \\ Changchun, China
}

\author{
J.X. Wang,J.G. Zhang \\ School of Armoured Force Technology Institute \\ Changchun, China
}

\begin{abstract}
As the auxiliary preheat device for vehicle, vehicle preheater has been widely adopted for vehicle cold starting, preheating and defrosting. The three-dimensional geometric model of preheater is established in this paper. The combustion process of preheater with different structures has been simulated. The simulation results reveal that the proper conical hood diameter could simulate the mixture between fuel and gas apparently and improve preheater combustion efficiency, combustion tube length affects the mixture between fuel and gas, the temperature distribution in the tube as well as also affects the lifetime of preheater, and different fin height has a great influence on the outlet temperature of preheater. Research results contribute to the design and development of preheater, and also put forward the improvement direction of preheater.
\end{abstract}

Keywords-vehicle preheater; preheater efficienc; flows field

\section{INTRODUCTION}

Vehicle preheater is very important technology for vehicle cold starting. As the independent heat source,it is widely used in engine warm-up in low temperature environment because it can work well and cannot be affected by the working condition of engine. It has lots of advantages such as starting fast, steady and high-efficiency [1]. Recently, vehicle preheater is widely researched by scholars. Eberspacher, as the primary preheater brand, has studied preheater in combustion technology, preheater control and emission levels [2]. In 2003, Zhao Kan, graduated from Chang An university, developed a new type of preheater matched with gas-fired automobile by using natural gas as a substitute fuel [3]. In 2006, Ye Zhou analysed the influence of the diameter, placement and direction of first air intake on the combustion temperature, and can be seen how exhaust emissions were affected by the geometrical parameters through the software FIRE [4]. In 2012, Guo Bin, through the improvement of the preheater structure, put forward two kinds of preheater structure models. One has double heat exchange water jacket, and the other has double heat transfer fuel gas jacket. Though the heat exchange efficiency has increased, they also increased the preheater volume [5].

The paper, on the basis of predecessors' research, improved the structure of conical hood diameter, combustion tube length and fin height in order to gain greater heat exchange efficiency and improve preheater.

\section{Vehicle Preheater StRUCtURE AND Working PRINCIPLE}

When the preheater works, fuel is drove by fuel pump and flows through fuel filter, fuel tap and fuel preheater device, then is injected into combustor by fuel spray nozzle finally. In the combustion chamber, the fuel and air inhaled by air fan from combustible mixture which are ignited by glow plug finally. The heat released through combustion transfer between the fin, heat transfer fuel gas jacket and the heat exchange water jacket. Finally, the exhaust emission is discharged through exhaust port. The preheater threedimensional model is showed in Fig. 1. The preheater rated power is $5 \mathrm{~kW}$.

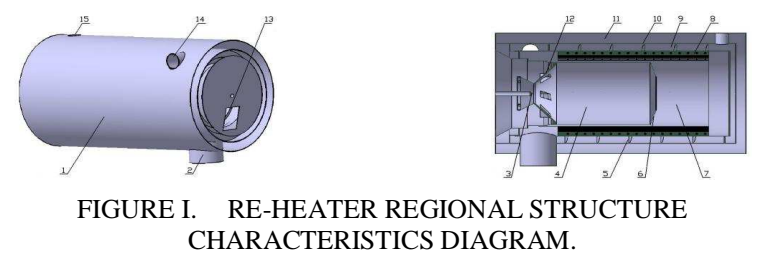

1. outside solid of insulating layer 2. exhaust port 3 . fuel inlet 4. first combustion chamber 5 . water conductor plate 6 . conical hood 7. second combustion chamber 8. fin 9. flow field 10. wall of preheater 11. insulating layer 12. air conductor plate 13. inlet of air 14. inlet of water 15 . outlet of water

\section{SimUlated ANALYSIS}

\section{A. The Influence of the Conical Hood Diameter on Combustion}

The conical hood diameter is the most important parameter of conical hood. With the diameter increasing, the flowing area of the first combustion chamber also increases. In order to know the influence of the conical hood diameter, five different diameters is set, shown in Tab.1. The diameter of original model is $90 \mathrm{~mm}$.

TABLE I. CONICAL HOOD DIAMETERS.

\begin{tabular}{cccccc}
\hline $\begin{array}{c}\text { The conical } \\
\text { hood diameter } \\
(\mathbf{d})\end{array}$ & d1 & d2 & d3 & d4 & d5 \\
\hline Values $(\mathbf{m m})$ & 50 & 60 & 70 & 80 & 90 \\
\hline
\end{tabular}


For observing the flow field near the conical hood, the preheater work process is simulated by CFD software. The velocity field near the conical hood is shown in Fig. 2. When the fuel gas flows from the conical hood, it would form a vortex on the second combustor. From the Fig. 2, it can be showed that there were some gas-poor dead zones when the diameter is $50 \mathrm{~mm}$ or $60 \mathrm{~mm}$. In gas-poor deed zones the gas cannot be mixed with fuel evenly, so the fuel could not be fully burned. When the diameter is $70 \mathrm{~mm}, 80 \mathrm{~mm}$ or $90 \mathrm{~mm}$, the gas could mix with fuel well. However, when the diameter is $80 \mathrm{~mm}$ or $90 \mathrm{~mm}$, the region of vortex is small, and it also causes that the mixture gas is burned poorly.

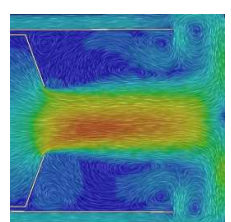

(a) $\mathrm{d} 1=50 \mathrm{~mm}$

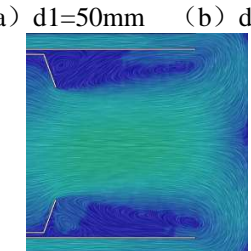

(d) $\mathrm{d} 4=80 \mathrm{~mm}$

(d) $\mathrm{d} 4=80 \mathrm{~mm}$ 12.0

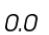

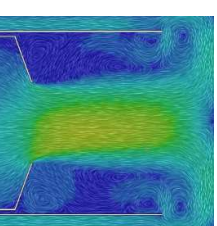

(b) $\mathrm{d} 2=60 \mathrm{~mm}$

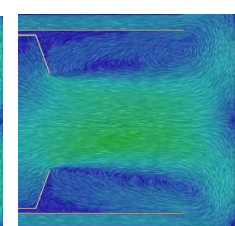

(c) $\mathrm{d} 3=70 \mathrm{~mm}$

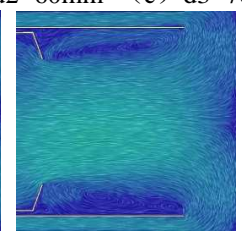

(e) $\mathrm{d} 5=90 \mathrm{~mm}$

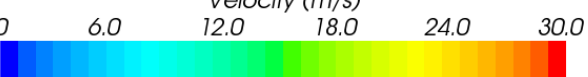

FIGURE II. SECOND COMBUSTION CHAMBER VELOCITY VECTOR DIAGRAM IN DIFFERENT CONICAL HOOD DIAMETER.

By simulation, the temperature field of the region near the vortex is obtained, which is shown in Fig. 3. From the Fig. 3, with the diameter increasing, the temperature of the vortex would increase at first, and then decrease. When the diameter is $70 \mathrm{~mm}$, the vortex region temperature is the highest. Through analyzing the gas flow and combustion state, it could be concluded that the requirement of flowing is meet when the diameter is $70 \mathrm{~mm}$ and the combustion is also promoted..

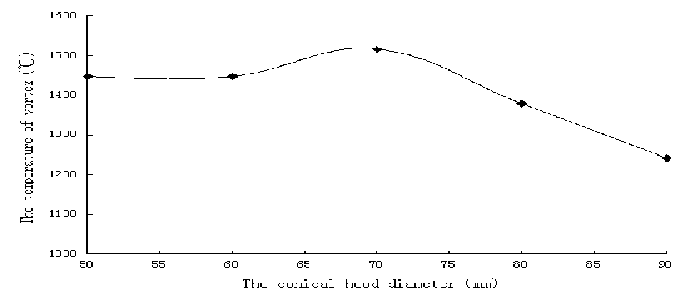

FIGURE III. THE INFLUENCE OF CONICAL HOOD DIAMETER VORTEX REGION TEMPERATURE.

\section{B. The Influence of the Combustion Tube Length on the Flow Field}

The combustion tube length is one of the important parameters of the combustion tube. With the length increasing, the residence time that the mixture gas stayed in the combustion chamber would increase [6]. In this paper, it designed five values of the combustion tube length is designed which were showed in Tab. 2.
TABLE II. COMbustion Tube Length Parameter VAlues

\begin{tabular}{cccccc}
\hline $\begin{array}{c}\text { The combustion } \\
\text { tube length }(\mathbf{L})\end{array}$ & $\mathbf{L}_{\mathbf{1}}$ & $\mathbf{L}_{\mathbf{2}}$ & $\mathbf{L}_{\mathbf{3}}$ & $\mathbf{L}_{\mathbf{4}}$ & $\mathbf{L}_{\mathbf{5}}$ \\
\hline Values (mm) & $\begin{array}{c}280 . \\
0\end{array}$ & $\begin{array}{c}290 . \\
0\end{array}$ & $\begin{array}{c}300 . \\
0\end{array}$ & $\begin{array}{c}310 . \\
0\end{array}$ & $\begin{array}{c}320 . \\
0\end{array}$ \\
\hline
\end{tabular}

Through the simulation about the combustion tube, flow field is obtained and is shown in Fig. 4. The figure shows that when the combustion tube length is short, there would be a large-scale region of vortex produced in the second combustor. But when the length is too long, though the region of vortex is small in the second combustor, the region of heat transfer would also have a large vortex. This situation should be avoided. From the Fig. 4, it is shown that when the length is $300 \mathrm{~mm}$, there would be an appropriate weak vortex, and this would not affect the gas flow. So when the combustion tube length is $300 \mathrm{~mm}$, the preheater efficiency is the best.

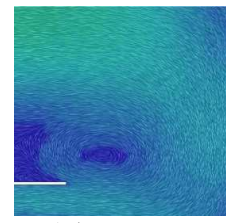

(a) $\mathrm{L} 1=280 \mathrm{~mm}$

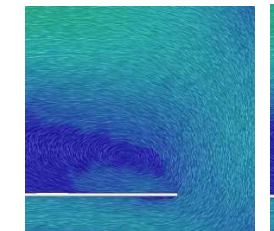

(d) $\mathrm{L} 4=310 \mathrm{~mm}$

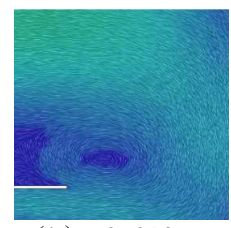

$2=290 \mathrm{~mm} \quad$ (c) $\mathrm{L} 3=300 \mathrm{~mm}$

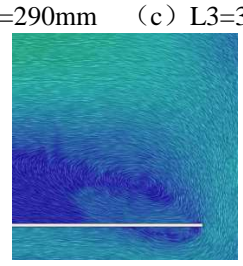

(e) $\mathrm{L} 5=320 \mathrm{~mm}$
FIGURE IV. GAS BAFFLE VELOCITY VECTOR DIAGRAM IN DIFFERENT COMBUSTION TUBE LENGTH.

\section{The Influence of the Fin Height on Combustion}

The preheater function is to heat circulation water. It is namely that the fuel is burned in the combustor, and then produces lots of high-temperature exhaust gases, which flows through the region of heat transfer to heat the circulating water. Only in this way the circulating water can be heated. The fin height in the region of heat transfer affects not only the heat transfer performance of preheater but also the flow field of the mixture gas, and then affects the performance of preheater. Five different fin heights were selected, which are shown in the Tab. 3. The original value of model is $12 \mathrm{~mm}$.

\section{TABLE III. Fin HeIght PARAmeter VAlues}

\begin{tabular}{cccccc}
\hline $\begin{array}{c}\text { The fin } \\
\text { height }(\mathbf{H})\end{array}$ & $\mathbf{H}_{\mathbf{1}}$ & $\mathbf{H}_{\mathbf{2}}$ & $\mathbf{H}_{\mathbf{3}}$ & $\mathbf{H}_{\mathbf{4}}$ & $\mathbf{H}_{\mathbf{5}}$ \\
\hline $\begin{array}{c}\text { Values } \\
(\mathbf{m m})\end{array}$ & 8 & 10 & 12 & 14 & 16 \\
\hline
\end{tabular}

By simulation, it can be attained that trend line of the velocity of exhaust port which changes with the fin height. It is shown in Fig. 5. It is shown that the velocity decreased with the fin height increasing. It is illustrated that the resistance of combustor increased with the fin height increasing. It is verified that with the fin height increasing, it impedes gas to flow and fuel to burn. 


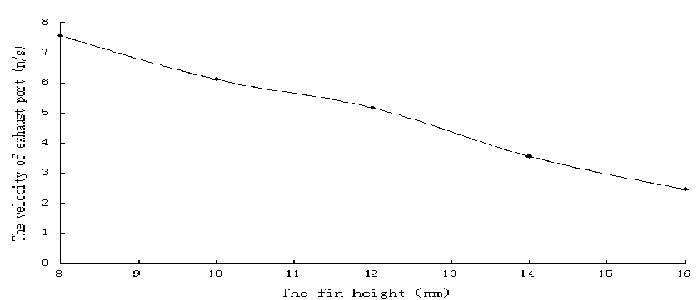

FIGURE V. THE INFLUENCE OF FIN HEIGHT ON EXHAUST VELOCITY.

The temperature of exhaust port changes with the fin height variation by simulation, which is shown in figure 6 . It is shown that the temperature rising with the fin height increasing. It illustrates that this improves the heat dissipation potential of preheater is improved with the fin height increasing. From the figure 5 , it can be seen that the requirements of combustor flow and the temperature of exhaust port are met.

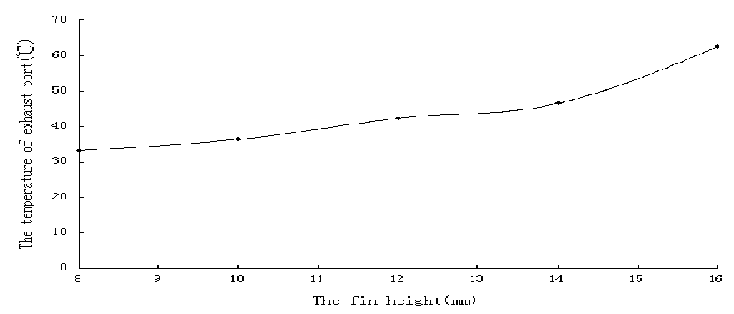

FIGURE VI. THE INFLUENCE OF FIN HEIGHT ON THE TEMPERATURE OF EXHAUST PORT.

\section{CONCLUSIONS}

By analyzing the influence of the conical hood diameter, the combustion tube length and the fin height on preheater, it is included that when the conical hood diameter is $70 \mathrm{~mm}$, the preheater not only can meet the requirement of the gas flow, but also can promote fuel combustion in the combustion chamber. When the combustion tube length is $300 \mathrm{~mm}$, vortex can be avoided in the heat exchanger structure flow field area, and temperature of secondary combustion chamber is uniform. When the fin height is $12 \mathrm{~mm}$, the flow requirement of the gas can be met in the combustion chamber, and temperature of the water outlet is ensured.

\section{REFERENCES}

[1] E.A.MÜLLER, C.H.ONDER, Optimal control of a fuel-fired auxiliary preheater for an improved passenger vehicle warm-up: Control Engineering Practice, pp. 664-675, 2009.

[2] Websto AG, Heater with an automizer nozzle: United States Patent and Trademark Office, US2005/0079458, 2005.

[3] Pan Shiyan, Research of Flow and Combustion in the Burner of a Spraytype Vehicle Heater. Jinan: Shandong University, pp. 1-4, 2010.

[4] Mao Huayong. An Experimental Study on Combustion Performance of Vehicle Fuel Heater. Automotive Engineering, pp. 1136-1146,2006.

[5] Hong Haihong. The Design and Development of Vehicle DIESEL-CNG Liquid Heater. Xi An: Changan University, pp. 2-5, 2005.

[6] Gong Fangting. Research on Enhancing Burner Performance for YJP-Q Series Vehicle Heaters. Tractors and farm transport vehicle, 37(6), pp. $82-88,2010$. 